\title{
Medicinal plants and their Anti-inflammatory effects in Hepatic disorders
}

\author{
Muhammad Jahangeer \\ Department of Biochemistry \\ Government College University Faisalabad, Pakistan. \\ ,Zahed Mahmood \\ Department of Biochemistry \\ Government College University Faisalabad, Pakistan. \\ Zainab Khursheed \\ , Department of Biochemistry \\ Government College University Faisalabad, Pakistan.
}

\section{Mehvish Ashiq}

Department of Chemistry The Women University Multan Pakistan.

\author{
Usman Ali \\ Department of Biochemistry \\ Government College University Faisalabad, Pakistan. \\ Shahzad Ismaeel \\ Department of Biochemistry \\ Government College University Faisalabad, Pakistan. \\ *Corresponding Author: Zahed Mahmood \\ Email: drzahiduaf2003@yahoo.com
}

\begin{abstract}
:
Herbal medicines are used as an alternative treatment to cure liver diseases and now a days become most commonly used therapy. Herbal medicines are derived from different parts of plants such as bark, roots, leaves, seeds and flowers. Silymarin, Glycyrrhizic acid, Camellia sinensis, Holy Basil and Long pepper are the medicinal plants that are effective and safe for the treatment of liver ailments. Almost 2 million deaths per year occur due to liver diseases while correct Statistics for liver diseases is not available but liver diseases are highly prevalent in Africa and Asia. By using medicinal plants, the prevalence of hepatitis, alcoholic fatty liver disease, non-alcoholic fatty liver disease, liver cirrhosis and hepatocellular carcinoma can be controlled. The increase in use of herbal medicines support the phenomenon of their effectiveness for the prevention of liver disorders. Scientists are now finding the benefits and evaluate the effect of different herbs on human health by using the scientific methods. Further research work should be done on herbal medicines to collect relevant data about effectiveness and safety of herbs that are used in pharmaceuticals as additional components now a days. This article discusses the common liver diseases, categories of herbs, WHO estimated prevalence of liver diseases worldwide and carcinogenic effects of herbal medicines associated with liver injury.
\end{abstract}

\section{Keywords:}

Herbal medicines, Non-alcoholic fatty liver disease, alcoholic fatty liver disease, Hepatitis, Liver cirrhosis, hepatocellular carcinoma, Prevalence

\section{Introduction}


Only a few options available for the treatment of common liver diseases such as liver cirrhosis, liver cancer, fatty liver disease and viral hepatitis that encouraged the researchers to use herbal medicine as an alternative treatment to cure liver diseases. From many centuries herbal medicines are used in eastern countries for the treatment of liver and other diseases related to internal organs of body and now herbal medicine become a most commonly used therapy. In herbal medicines, different parts of plants are used for medical purposes such as bark, roots, leaves, seeds and flowers. Scientists are now finding the benefits and evaluate the effect of different herbs on human health by using the scientific methods. In recent years, the study on herbal medicines shows that many herbs can be used for treatment of liver ailments such as silymarin, glycyrrhizic acid, Camellia sinensis, holy Basil and long pepper. The increase use of herbal medicines shows that they are effective and safe because they are obtained from natural plants (Rajaratnam et al. 2014).

There are variety of pharmaceutical drugs that induce hepatotoxicity as well as liver damage (Fig.1). For example; the use of Rifampicin leads to hyperbilirubinaemia while some drugs cause cytotoxic injury, Cholestatic injury, fatty liver disease either alcoholic or non-alcoholic, cirrhosis, phospholipidosis, liver tumors and chronic hepatitis (Fig. 1). The severity of injury depends upon the drug mechanism for which either parent compound or intermediate compound may be responsible (Kshirsagar et al. 2008).

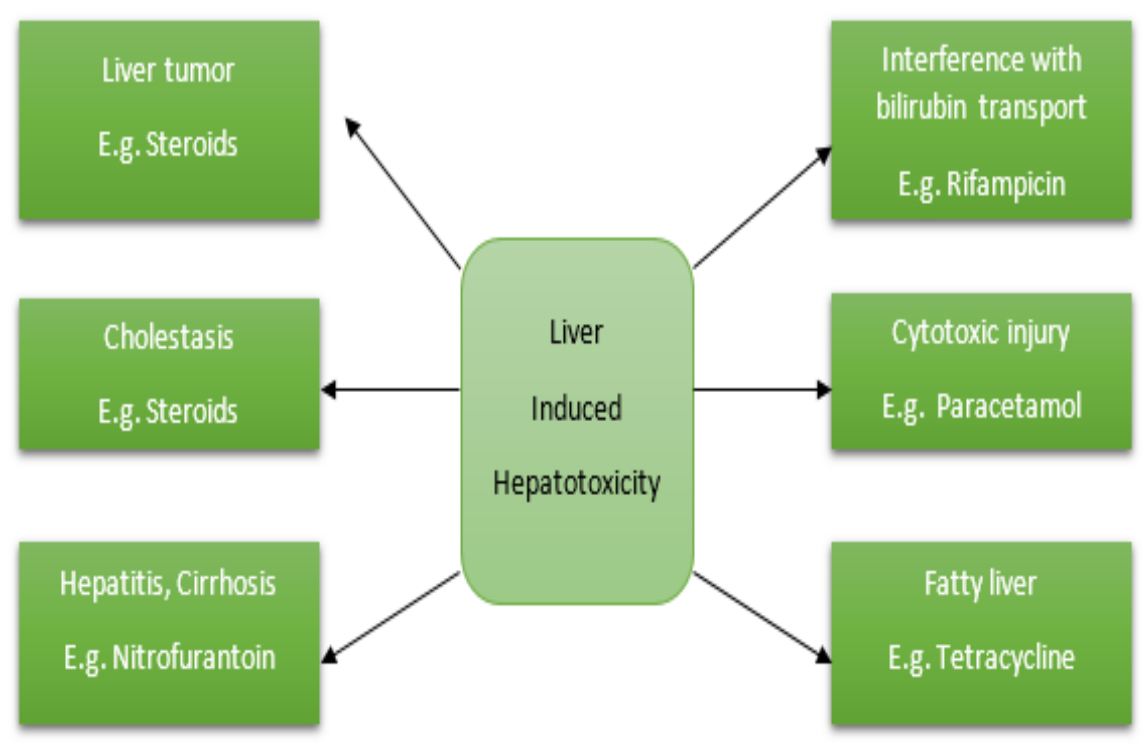

Fig.1: Drugs induced liver injury

Almost 2 million deaths per year occur due to liver diseases in which 1 million are due to liver cancer and viral hepatitis while one million occur due to liver cirrhosis. Correct Statistics for liver diseases is not available but liver diseases are highly prevalent in Africa. The rate of chronic and acute liver disease is expected to increase worldwide because they are prevalent with high morbidity and mortality rates (Mokdad et al. 2014). Recent studies suggest that the main cause of death is liver cirrhosis and liver cancer. Liver diseases contribute to high morbidity rate globally and responsible for low quality of life that can leads to the increase rate of mortality. The $11^{\text {th }}$ most common cause of death is liver cirrhosis that leads to 1.16 million deaths per year and $16^{\text {th }}$ most common cause of death is liver cancer which leads to 788,000 deaths per year. $3.5 \%$ deaths occur due to liver disorders (Asrani et al. 2013). The mortality rate by liver cirrhosis and hepatocellular carcinoma till 2015 in Asia is estimated and data is available in Global Health Estimates of 2015 as written in table 1. 
Table.1: Mortality rate by liver cirrhosis and HCC

\begin{tabular}{|l|l|l|l|l|}
\hline $\begin{array}{l}\text { Geographical } \\
\text { distribution }\end{array}$ & Global rank & $\begin{array}{l}\text { Deaths occur by } \\
\text { cirrhosis }\end{array}$ & $\begin{array}{l}\text { \%age of total deaths } \\
\text { by liver diseases }\end{array}$ & Death occur by HCC \\
\hline World & 11 & 1,162 & $2.1 \%$ & 788 \\
\hline East Asia & 13 & 328 & $2.0 \%$ & 547 \\
\hline Central Asia & 17 & 115 & $1.2 \%$ & 78 \\
\hline South Asia & 10 & 314 & $2.5 \%$ & 38 \\
\hline
\end{tabular}

\section{History of herbal medicines}

According to written record the research on herbs was started 5000 years ago while Ancient Egyptians wrote information about 850 plants that could be used as medicine included garlic, cannabis and mandrake. However, in Early Middle Ages the only known source for medical knowledge was Benedictine monasteries. Arab travelers have significantly expanded the earlier knowledge of herbal medicine because they got access to the herbs of distinct places including China and India. The use of herbs to treat the disorders in middle ages was become the effective way for formulation of future medicines. About 122 compounds that had used in modern medicine, $80 \%$ of these are derived from plant sources. The $15^{\text {th }}, 16^{\text {th }}$ and $17^{\text {th }}$ centuries were the age in which great research on herbs and medicinal plant was done. Development of different analytical tools had increased the use of herbal medicines such as pharmaceuticals (opium, aspirin, quinine) using by physicians now a days were used as herbal remedies for long time (Table 2). According to an estimate of World Health Organization, $80 \%$ of Asian and African population use herbal medicines for health care and $25 \%$ of medicines are derives from plants that are in use now a days. Many drugs with herbal constituents have been developed and pharmaceutical companies started the large scale development of drugs that are effective and can be used for the treatment of different diseases (Cascado, 2016).

Table 2: Important pharmaceutical drugs and their sources

\begin{tabular}{|l|l|}
\hline Medicine & Plant source \\
\hline Aspirin & Willow bark \\
\hline Digoxin & Foxglove \\
\hline Quinine & Cinchona bark \\
\hline Morphine & Opium poppy \\
\hline
\end{tabular}

\section{Categories of herbals}

Herbal are divided into 3 broad categories in which first are those herbals that directly derived from plants. There characteristics depend on geographical and weather conditions where they are grown. Second category is of botanical herbals that are used to synthesize the effective drugs in combination and launched the pharmaceutical industry. Only $15 \%$ fraction of drugs is obtained from plants now while more than $80 \%$ of drugs were obtained from plants in mid 1980s. The third category is of commercial herbals that are synthesized in industry and sold under the trade names have become the predominant type of herbal medicines used to treat illnesses in western countries. These market products consist of multiple constituents ranging from 2 to more than 12 and vitamins as additional components. Herbs contain unique features because of many plant derived additional compounds, vitamins, antioxidants that enhance our immunity by fighting 
against toxins and foreign particles that enter in our body. Some anti-cancerous drugs are also obtained from herbs such as alkaloids originated from berberine (Seeff et al. 2015).

\section{Herbal medicines use for liver diseases}

In recent studies, liver is described as an organ of immune system and have significant role in innate and adaptive immunity. But this fact cannot be denied that liver is the primary target for herbal toxicants. Herbal medicine does not consist of a single extract because it is the mixture of many plant extracts to produce therapeutic effects but unfortunately there are some plant extracts in the mixture that have hepatotoxic effects as well (Balaban et al. 2017). In spite of some limitations, herbal medicines are widely used for the treatment of various liver diseases and have shown favorable effects in clinical trials or in cell culture (Stickel et al. 2007). Botanical drugs that are used for treatment of liver diseases are:

\section{Silymarin}

Silybum marianum (ingredient of milk thistle) have been used from $16^{\text {th }}$ century to treat liver disease. Its major components are flavonoids in which silibinin is used in pharmaceutical industry to standardized the pharmaceutical products and biologically most active compound in flavonoids family. Flavonoids are polyphenolic compounds. Their oxidation generates less than 5000 compounds with different properties. Different studies have shown that silymarin provides protection against liver toxicities results from tetra chloromethane and carbon tetrachloride. Hepatotoxic effects are provided by different mechanisms such as stimulation of DNA polymerase, antioxidant activity, increase in glutathione concentration and maintenance of hepatocellular membrane (Fig. 2). The most effective property of silymarin is that it inhibits the permeability of cell associated with alterations in membrane lipids by influencing the lipoprotein secretion and uptake. It is used for the treatment of liver cirrhosis, Jaundice as well as hepatitis (Vargas et al. 2014).

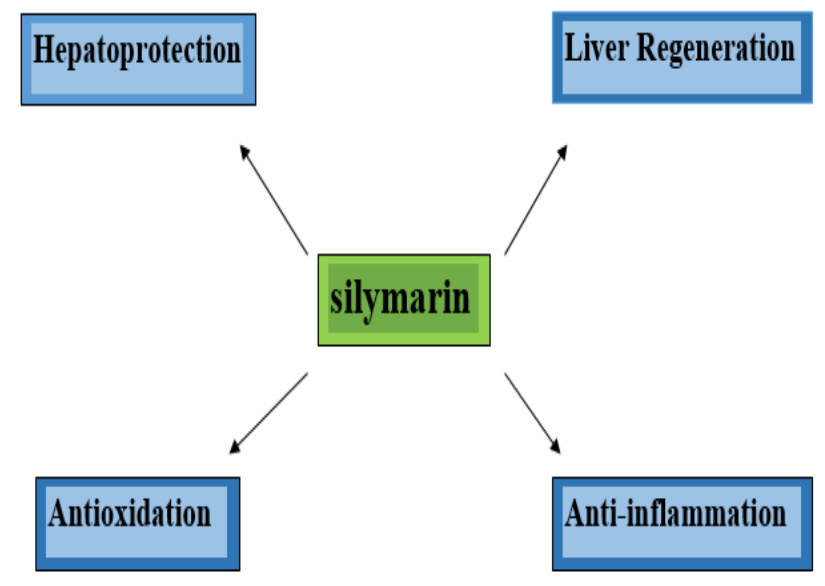

Fig. 2: Silymarin biological functions

Silibinin reduce the synthesis of triglycerides in liver produces by carbon tetrachloride. Silymarin is also induced hepatoprotection against liver injury by paracetamol. Silymarin inhibits the P450 detoxification system by effecting the enzymes of CYP system by providing protection against free radicals generated by enzymes of detoxification system (Bahmani et al. 2015).

\section{Glycyrrhizic Acid}


The natural compounds have been used for treatment of liver diseases because of their low toxicity and high efficacy. Glycyrrhizic acid is hepatoprotective compound found in the roots of plant Glycyrrhiza glabra. It is a triterpene glycoside that possesses biological as well as pharmacological properties. It acts as antiviral and anti-inflammatory drug in liver diseases (Li et al. 2014).

Glycyrrhizin is 30 to 50 times sweeter than sugar and used for giving flavours to tobacco. It is used in the treatment of asthma, malaria, ulcer, liver diseases and abdominal pain. Glycyrrhizic acid protect the liver cells from free radicals produced by galactosamine to increase the metabolism of drugs. In japan it is called Stronger Neominophagin C (SNMC) and use to treat inflammation of liver especially in the treatment of hepatitis C. SNMC contain 3 main components include cyctein, glycine and glycyrrhizin (Table). It has eldosteron like effect and ability to produce fluid for hypertension. It lowers the level of ALT and thus have anti-inflammatory effects on liver (Hidaka et al. 2007).

\section{Table 3: SNMC components with percentage}

\begin{tabular}{|l|l|}
\hline SNMC components & percentages \\
\hline Cysteine & $0.1 \%$ \\
\hline Glycyrrhizin & $0.1 \%$ \\
\hline Glycine & $2 \%$ \\
\hline
\end{tabular}

\section{Longpepper}

Long pepper is also used in the treatment of liver diseases because it is effective, easily available, have high efficacy and affordable, long pepper is obtain by plant Fructus Piperis Longi which is used in herbal medicine system as an alternative treatment. It can increase the antioxidant activities in liver and provide protection against inflammation of liver, cancer and toxicity. This herbal plant has ability to reduce the bilirubin content which prevent the jaundice as well as have ability to reduce the activity of alanine aminotransferase that leads to the development of liver cirrhosis. Extract of this plant have potential against hepatitis B virus and hepatoprotecive affects in case of chronic liver diseases. Long pepper does not have any adverse effect if it is used in high doses but some researchers demonstrated that this plant should not be used during high pregnancy or lactation (Xiong et al. 2017).

\section{Holy Basil}

Holy basil is known as Tulsi and its scientific name is Ocimum sanctum $L$. In traditional and herbal medicine system including Chinese, Greek, Siddha, Unani and Roman it is known as hepatoprotective plant which contain important ingredients that possess anti-inflammatory properties. This herb do not have any side effects on human health and can be use as green vegetable. In case of liver diseases, holy Basil is used in combination with silymarin to develop hepatoprotective activity. It can also be used as radioprotective agent (Baliga et al. 2013).

\section{Camellia sinensis}

Camellia sinensis is commonly called green tea which is counted in the popular beverages worldwide. It consists of flavonoids that represent high level of antioxidant properties. The most important flavonoid in green tea is Catechins found in the leaves of camellia plant and possess antiviral activity as well as decrease the rate of oxidative stress. It also effects the lipid metabolism and decrease the level of cholesterol thus it can be used as an effective herb in fatty liver disease because it enhances the energy utilization of body. Experimental studies shows that green tea can be beneficial for treatment of nonalcoholic fatty liver disease 
by maintaining the homeostasis and inflammation of internal organs of body in which most important organ is liver (Park et al. 2011).

\section{Curcumin (Turmeric)}

Curcumin (common name turmeric) is a phenolic substance obtained from plant Curcuma longa which is used as coloring and flavoring agent in food as well as use in many drugs as an essential component of pharmaceutical drugs. Different studies suggest that curcumin has anti-cancer, antioxidant, anti-inflammatory and hepateprotective effects which act by change in the level of gene expression and signalling pathway. Liver Cirrhosis if left untreated it will lead to liver cancer so curcumin is the best herbal medicine that can be used for the treatment of both diseases and prevent the progression of cirrhosis to carcinoma by its anticancer property (Akbar et al. 2018).

\section{Natural plants for the treatment of liver diseases}

Some natural plants are also effective in prevention and treatment of liver diseases by promoting the health of liver (Table 4). These plants provide anti-oxidant activity, hepatoprotectivity and inhibition of carcinogenesis by cell cycle arrest. Natural foods are also beneficial for the health of patients suffering from liver diseases (Zhang et al. 2013).

\section{Table 4: Health effects of natural plants on liver}

\begin{tabular}{|l|l|l|}
\hline Natural plant & Effect & Adverse reactions \\
\hline Coffee & $\begin{array}{l}\text { Prevent liver fibrosis, cirrhosis, } \\
\text { Liver cancer, } \\
\text { decreasing mortality, }\end{array}$ & Not mentioned \\
\hline Apple & $\begin{array}{l}\text { Antioxidant, } \\
\text { inhibit apoptosis, }\end{array}$ & Not mentioned \\
\hline Resveratrol & $\begin{array}{l}\text { lipid metabolism improved, } \\
\text { decrease the incidence of NAFLD } \\
\text { (nonalcoholic fatty liver disease ) }\end{array}$ & Not mentioned \\
\hline
\end{tabular}

\section{Coffee}

Several studies shows that coffee reduces the risk of liver cancer and cirrhosis. Daily intake of 2 cups of coffee reduces the risk or liver diseases due to its antioxidant effects. However, there is no evidence that increase use of coffee is beneficial for health. Coffee reduces the severity of non-alcoholic fatty liver disease so patients with liver diseases are encouraged to uptake 2 cups of coffee daily. Many studies demonstrated that increase coffee consumption is indirectly associated with liver ALT (alanine-aminotransferase) and AST (aspartate-aminotransferase) levels (Wadhawan \& Anand, 2016).

\section{Apple}

Against many chronic liver diseases, apple and citrus fruits have many beneficial effects because apple is rich in antioxidants. Research on rats confirmed that apple is beneficial in case of liver impairment while another study revealed that apple have hepatoprotective effect against hepatocyte apoptosis induced by carbon tetrachloride $\left(\mathrm{CCL}_{4}\right)$. But if a person has allergy from citrus fruit and suffering from liver disease, the apple and citrus fruits cannot be given to them because it may leads to them oral allergy syndrome (Sharma et al. 2016)

\section{Resveratrol}

It is a plant phytoalexin found in many plants such as red grapes, mulberries, sickle pod and peanuts. Resveratrol improves the lipid metabolism and protect against fatty liver diseases such as non- 
alcoholic. It extends the lifespan in living organisms by activation of sirtuins. Green vegetables can be used against infection of liver because they provide hepatoprotective effects. Many natural foods consist of components and natural agants that are advantageous to liver health such as terpenoids, vitamins, curcumin, carotenoids and rosemary essential oil (Zhao et al. 2016).

\section{Herbal treatment for Common liver diseases}

\section{Hepatitis}

Hepatitis is an inflammation of liver caused by five types of viral agents that are named as Hepatitis A Virus (HAV), Hepatitis B Virus (HBV), Hepatitis C Virus (HCV), Hepatitis D Virus (HDV) and Hepatitis E Virus (HEV). Each type of virus is responsible for different type of hepatitis like A, B, C, D, E. Autoimmune hepatitis is another possible cause of hepatitis in which body makes antibodies against liver tissues. Liver performs significant functions including bile production, breakdown of fats, proteins and carbohydrates, synthesis of albumin as well as activation of enzymes that perform different body functions such as those enzymes involve in glycogen storage (Mysore \& Leung, 2018).

Hepatitis is divided into two categories; first one is acute and short-term condition in which person can recover in less than six months. Hepatitis A and E fall into this category because both are acute and short term. Second one is chronic and persistent condition that lasts for more than 6 months. Hepatitis B, C and D fall into this category. Symptoms for acute and chronic hepatitis are also different. In case of hepatitis A and E the symptoms appear too quickly such as weight loss, abdominal pain, fatigue, dark urine and yellowish skin (jaundice) while in case of chronic hepatitis (B, C, D) symptoms occur too slowly and hard to notice. People with hepatitis $\mathrm{B}$ and $\mathrm{C}$ are at greater risk of developing serious health problems such as cirrhosis, chronic liver disease and hepatocellular carcinoma described in figure (Mysore \& Leung, 2018).

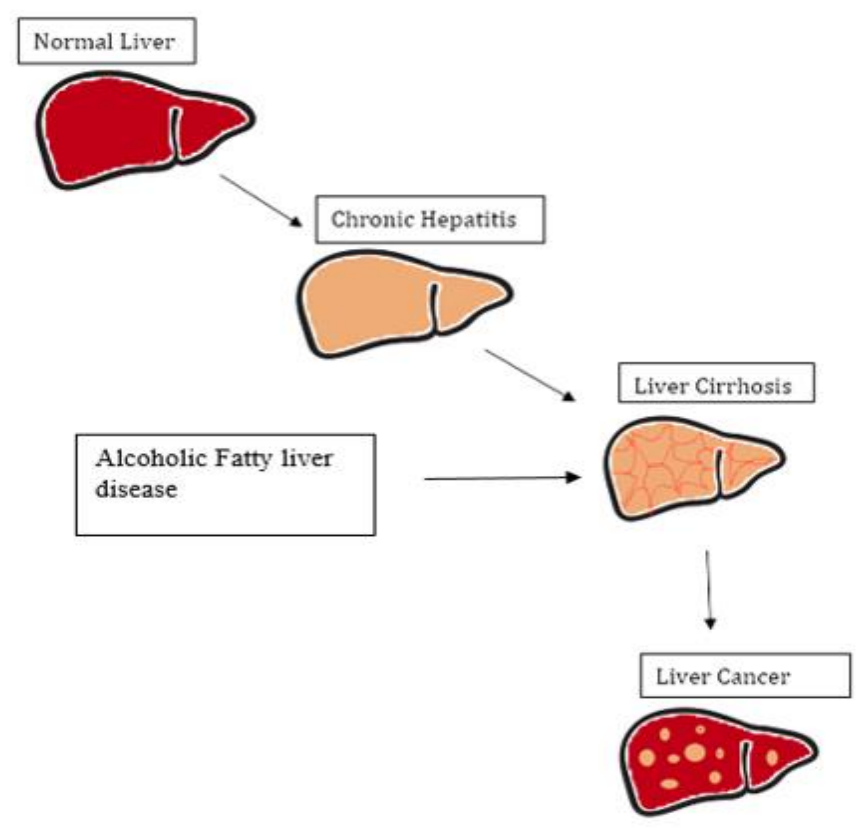

Fig. 3: Hepatitis association with serious liver problems

Viral hepatitis is the $10^{\text {th }}$ most common cause of increase in mortality rate worldwide. Hepatitis B and hepatitis C are responsible for $96 \%$ of deaths of patients suffering from hepatitis in which hepatitis B 
ratio is $66 \%$ and hepatitis $\mathrm{C}$ ratio is $30 \%$ (Fig. 3) While hepatitis A accounts for $0.8 \%$ and hepatitis E cause $33 \%$ deaths worldwide (Stanaway et al. 2016).

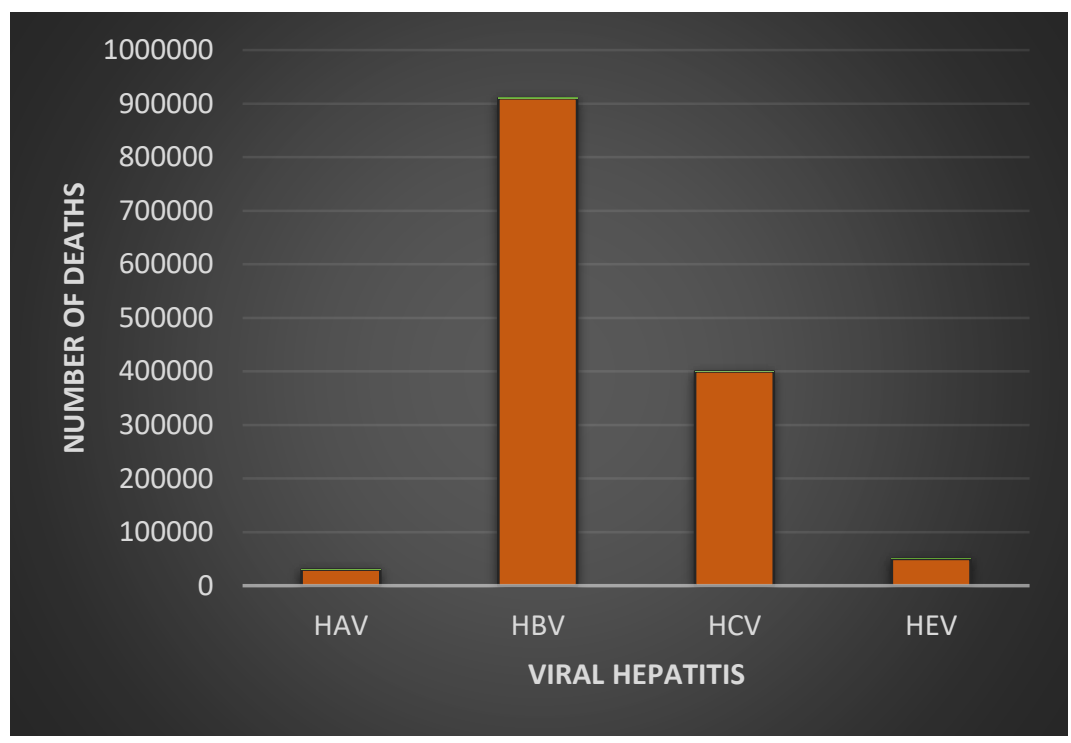

Fig. 4: Death from viral hepatitis

\section{Hepatitis A}

Hepatitis A is caused by poor hygiene and sanitation conditions as well as containment of drinking water that's why it is most common in the areas that have low income while the area with high income have low ratio of persons suffering from hepatitis A. Vaccine is available for hepatitis A that reduces the risk of disease in high income countries such as Europe and America (Franco et al. 2012).

\section{Hepatitis B}

Hepatitis B virus increases the risk of hepatocellular carcinoma. 10 genotypes of HBV have been isolated worldwide. 240 million people are infected by hepatitis B virus and at greater risk of developing the liver cancer. If it is not treated it may become chronic and leads to liver cirrhosis, liver failure or liver cancer. It spreads when person who has hepatitis B come in contact with the body fluids of healthy persons. Its symptoms include Jaundice, fever, vomiting and nausea (Tong \& Revill, 2016). Prevalence of hepatitis B in WHO region in 2015 is about $1.3 \%$ of population in all regions described in table (Shankar et al. 2016).

\section{Table 5: Region wise prevalence of hepatitis B}

\begin{tabular}{|l|l|l|l|}
\hline WHO region & Best & Lower & Higher \\
\hline African Region & $3.0 \%$ & $2.0 \%$ & $4.7 \%$ \\
\hline Region of Americas & $0.2 \%$ & $0.1 \%$ & $0.5 \%$ \\
\hline East Mediterranean & $1.6 \%$ & $1.2 \%$ & $2.1 \%$ \\
\hline
\end{tabular}


Pakistan Journal of Biochemistry and Biotechnology (PJBB) Vol. 1, No.21 (2020), pp. 32-50

\begin{tabular}{|l|l|l|l|}
\hline European Region & $0.4 \%$ & $0.2 \%$ & $0.8 \%$ \\
\hline South-East Asia & $0.7 \%$ & $0.5 \%$ & $1.6 \%$ \\
\hline Western Pacific & $0.9 \%$ & $0.6 \%$ & $1.3 \%$ \\
\hline Total & $1.3 \%$ & $0.9 \%$ & $2.2 \%$ \\
\hline
\end{tabular}

HBV is a double stranded DNA virus and belongs to the family Hepadnaviridae which results in acute or chronic hepatitis. DNA polymerase is used in the replication of HBV but due to lack of proofreading there is the chance of higher number of mutations which may be manipulated to treat the hepatitis B virus. There are $10 \mathrm{HBV}$ genotypes which further classified into multiple sub-genotypes depends on geographical distribution. Recombination of different types of HBV genotypes create challenges for hepatitis B treatment that's why herbal medicines are used as an alternative treatment (Lin \& Kao, 2017). Estimated prevalence of HBV by WHO in 2015 can be represented graphically in Fig. 5.

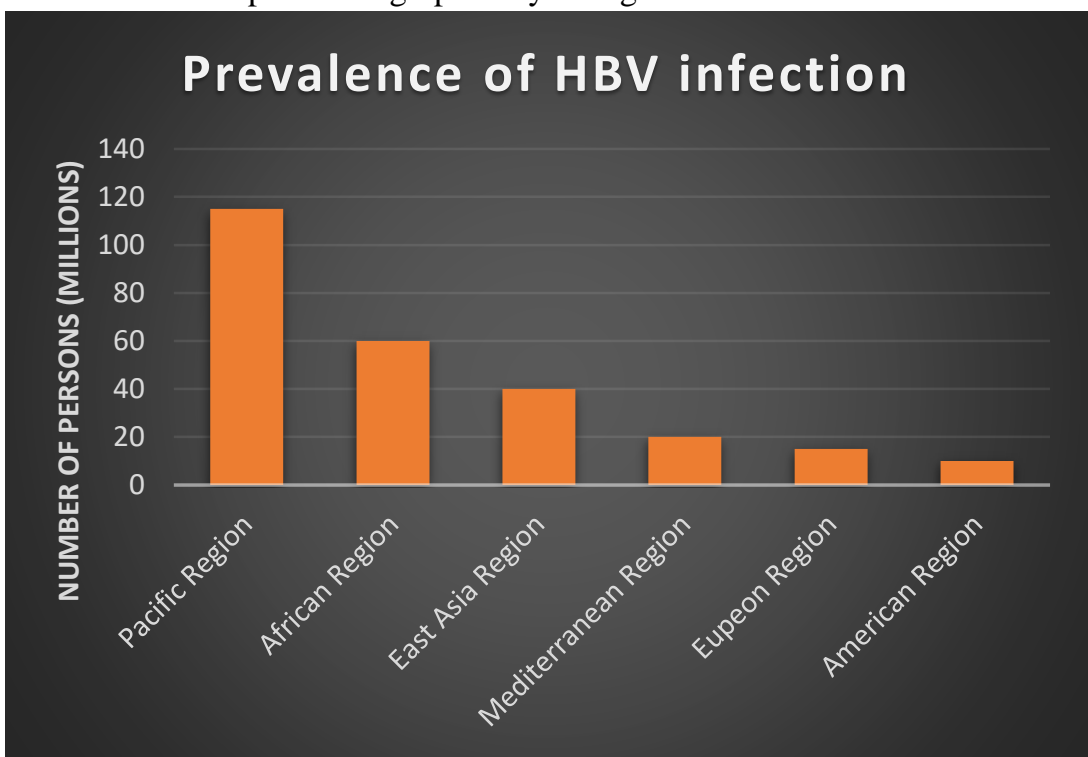

Fig. 5: Estimated prevalence of Hepatitis B virus infection by WHO

\section{Hepatitis C}

Hepatitis $\mathrm{C}$ is caused by HCV which spreads through blood transfusions with HCV infected person (Fig. 6). The patients who went through organ transplantation are also at greater risk of developing the both acute and chronic hepatitis C. Unfortunately, there is no vaccine available for treatment of hepatitis C that's why people use herbal remedies to get rid of this contagious disease. If the persons have strong immune systems that can fight against this disease then no treatment is suggested by doctor because their immune system is able to clear the infection on its own. Some interferons and antivirals are used for the treatment of HCV but it leaves permanent side effects so herbal medicines are gaining preference for treatment of hepatitis $\mathrm{C}$ virus because of very low or no toxic effects. The highest percentage of hepatitis $\mathrm{C}$ is seen in 6 countries with different genotypes (Table 6). Genotype 1 is responsible for $60 \%$, genotype 3 is responsible for $36 \%$ and genotype 4 is responsible for $4 \%$ of all infections (Blach et al. 2017).

Table 6: Genotypes of Hepatitis c and their percentage 
Pakistan Journal of Biochemistry and Biotechnology (PJBB) Vol. 1, No.21 (2020), pp. 32-50

\begin{tabular}{|l|l|l|}
\hline Country & Genotype & Percentage \\
\hline China & 1 & $58.2 \%$ \\
\hline Pakistan & 3 & $79 \%$ \\
\hline India & 3 & $64.1 \%$ \\
\hline Egypt & 4 & $90 \%$ \\
\hline Russia & 1 & $54.9 \%$ \\
\hline US & 1 & $72.5 \%$ \\
\hline South Africa & 5 & $35.7 \%$ \\
\hline South Asia & 6 & $95.6 \%$ \\
\hline
\end{tabular}

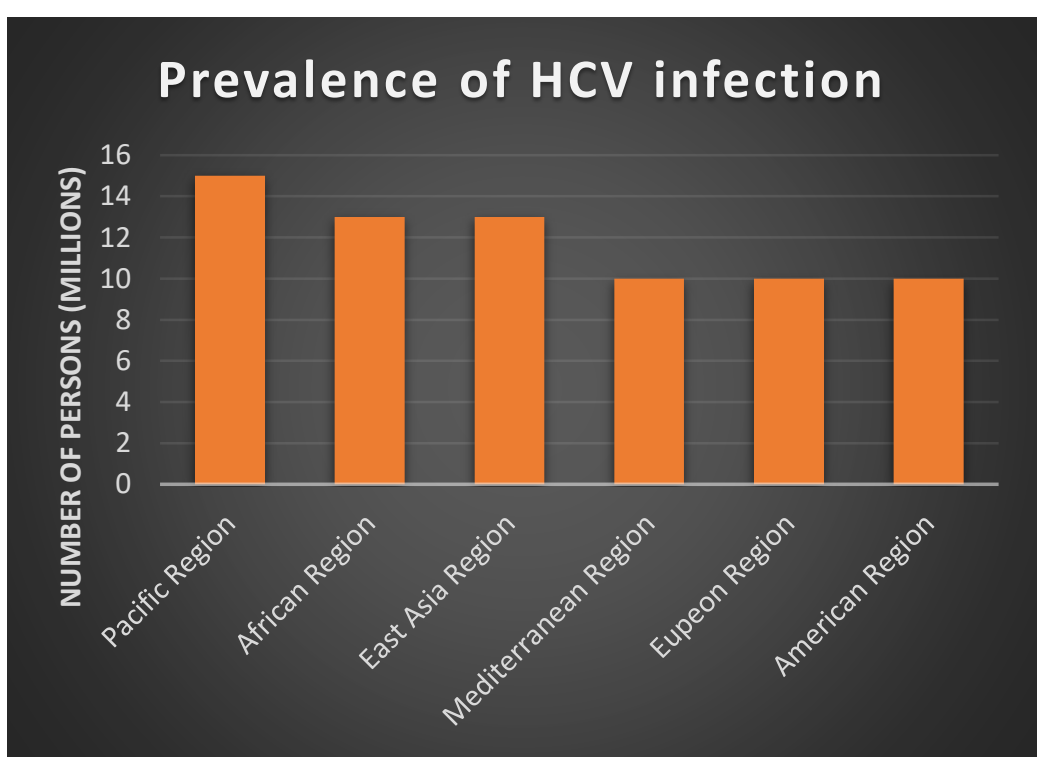

Fig. 6: Estimated prevalence of HCV by WHO

\section{Hepatitis D}

Hepatitis D virus is an incomplete virus and spreads through exposure to blood of an infected person. The persons who are already suffering from hepatitis B virus, HDV can infect only those persons. This phenomenon is called superinfection which refers that HDV acts as a cofactor for HBV in which the persons infected by hepatitis B are also co-infected by hepatitis D. In Mongolia, $60 \%$ of HBV patients are also infected with HDV while vaccinations used for HBV virus also have potential to prevent HDV (Chen et al. 2017).

\section{Hepatitis E}

Hepatitis $E$ is most common in Asia and Africa and caused by 1 and 2 genotype out of 8 genotypes in hepatitis E virus. Hepatitis E spreads through fecal oral transmission and leads to liver failure. Vaccine for HEV is only available in China and has not been licensed in other countries (Debing et al. 2016). 


\title{
Herbal treatment of hepatitis
}

Glycyrrhizic acid have antiviral activity and can be used to treat viral hepatitis because it can act as cell entry inhibitor for hepatitis virus. Now a days it has become commonly used herb in Japan for treatment of chronic hepatitis $\mathrm{B}$ and $\mathrm{C}$ because it can inhibit the penetration of virus into host cell by its antiviral mechanism of action (Fig. 7). Glycyrrhizic acid is phytochemical that can affect the adsorption of virus on host cell, after adsorption the viral coat remain outside while uncoated viral particle undergone the stages of replication, transcription and translation to produce viral proteins. The whole process of nucleic acid synthesis to viral protein synthesis in host cell can be inhibited by glycyrrhizic acid by following mechanism explained in figure. Because of this antiviral mechanism of action, the glycyrrhizic acid is now been used as an effective herbal treatment for hepatitis (Wu, 2016).

\section{Fatty liver disease}

Fatty liver refers to the accumulation of fats in liver. Small amount of fats is always present in our liver because liver is primary organ of our body that carries out metabolic reactions but accumulation of too much fats leads to the serious health problems. The fatty liver disease is classified into two subclasses: Alcoholic fatty liver disease and Non-alcoholic fatty liver disease.

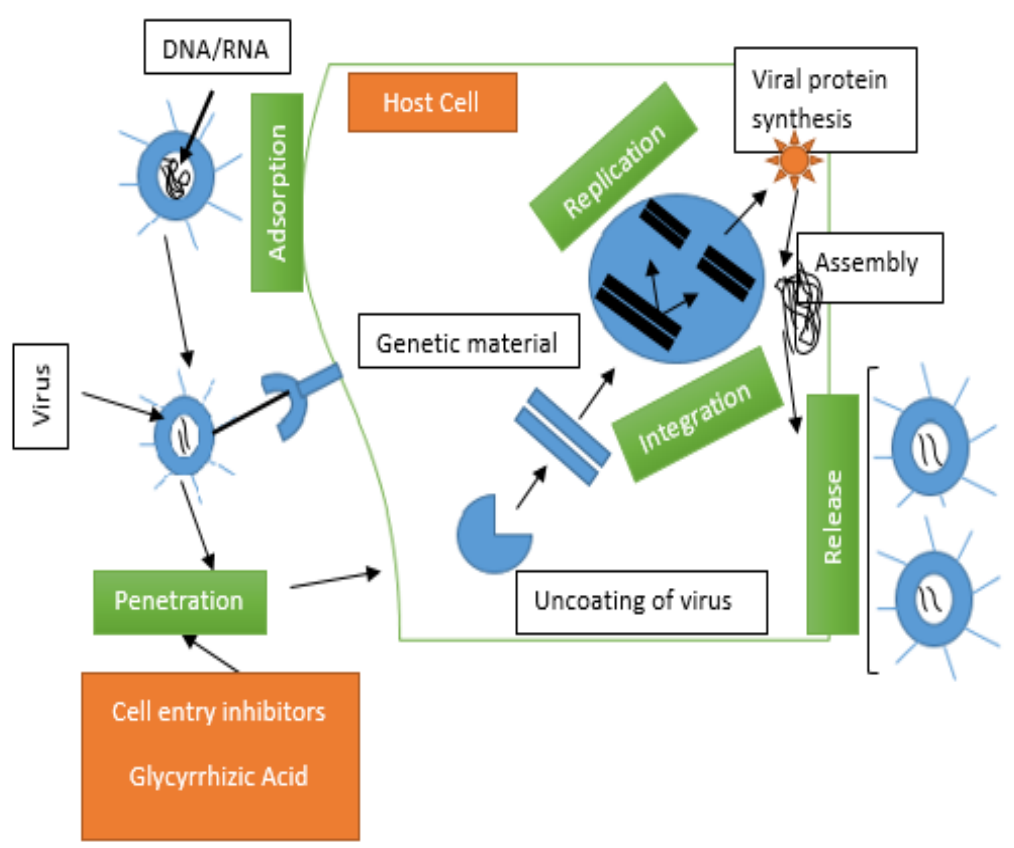

Fig.7: Glycyrrhizic acid mechanism of action in chronic hepatitis

\begin{abstract}
Alcoholic fatty liver disease
Alcohol-induced liver disease (AALD) is the leading causes of liver diseases throughout the world. The mechanism for the generation of ROS in different cellular organelles by alcohol that results in liver diseases is explained in figure. According to the World Health Organization 2 billion people consume alcohol, and around 75 million people have alcohol related diseases in which alcoholic fatty liver disease is most common (Rehm et al., 2013). Ethanol is converted into acetaldehyde in cytosol and generate reactive that leads to DNA
\end{abstract}


damage and lipid peroxidation which results in alcoholic fatty liver disease or even hepatocellular carcinoma (Prasad et al. 2017).

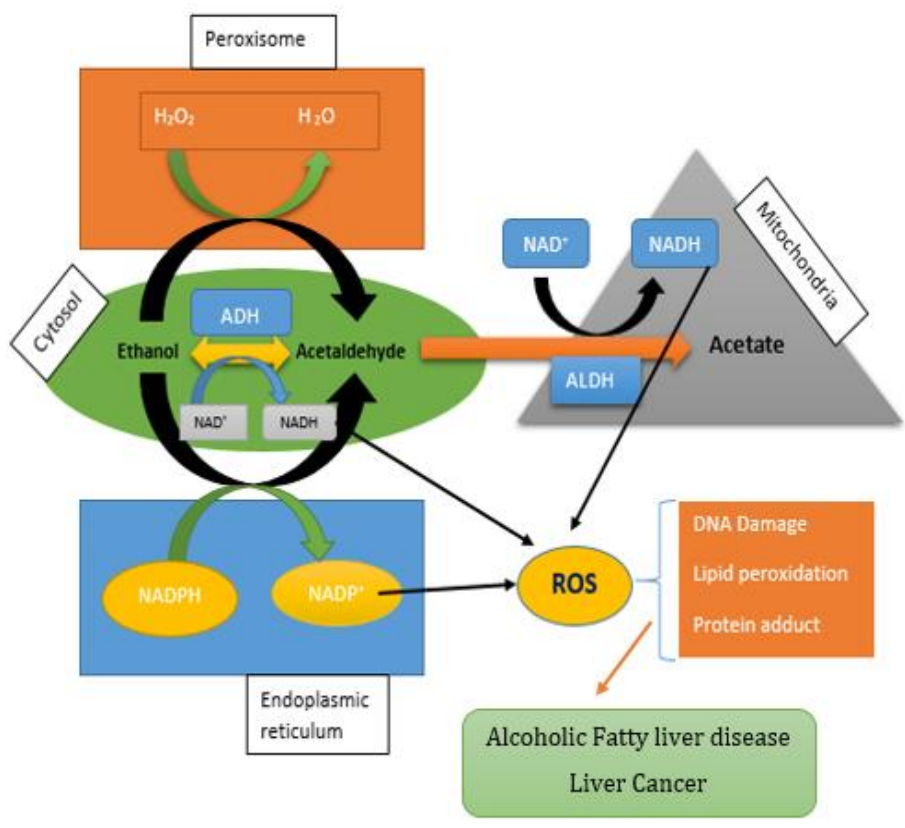

Fig. 8: Generation of ROS by ethanol contributing to Fatty liver disease

\section{Non-alcoholic fatty liver disease}

In this disease there are 2 conditions either it is non-alcoholic fatty liver with mild inflammation or nonalcoholic steatohepatitis with distinct degrees of liver cancer and cirrhosis. It occurs in co-existance with obesity and there is higher risk of developing NAFL if patient is already suffering from obesity. In last four decades, the rate of incidence of obesity has increased 4 folds and rate of non-alcohlic fatty liver disease is also increased 4 folds which proves that the prevalence of NAFL is associated with obesity (Rinella \& Charlton, 2016).

\section{Herbal treatment of Fatty liver disease}

AFLD, NAFLD is caused by environmental as well as genetic factors, different researches have been conducted to explain the mechanism of Silymarin to control the fatty liver disease (Fig. 9). The therapeutic targets for silymarin are triglycerides, reactive oxygen species, interleukins, interferons and free fats by which it decreases the risk of alcoholic fatty liver disease. In clinical practice, the patients have gone through successful treatment by silymarin (Federico et al. 2017). 


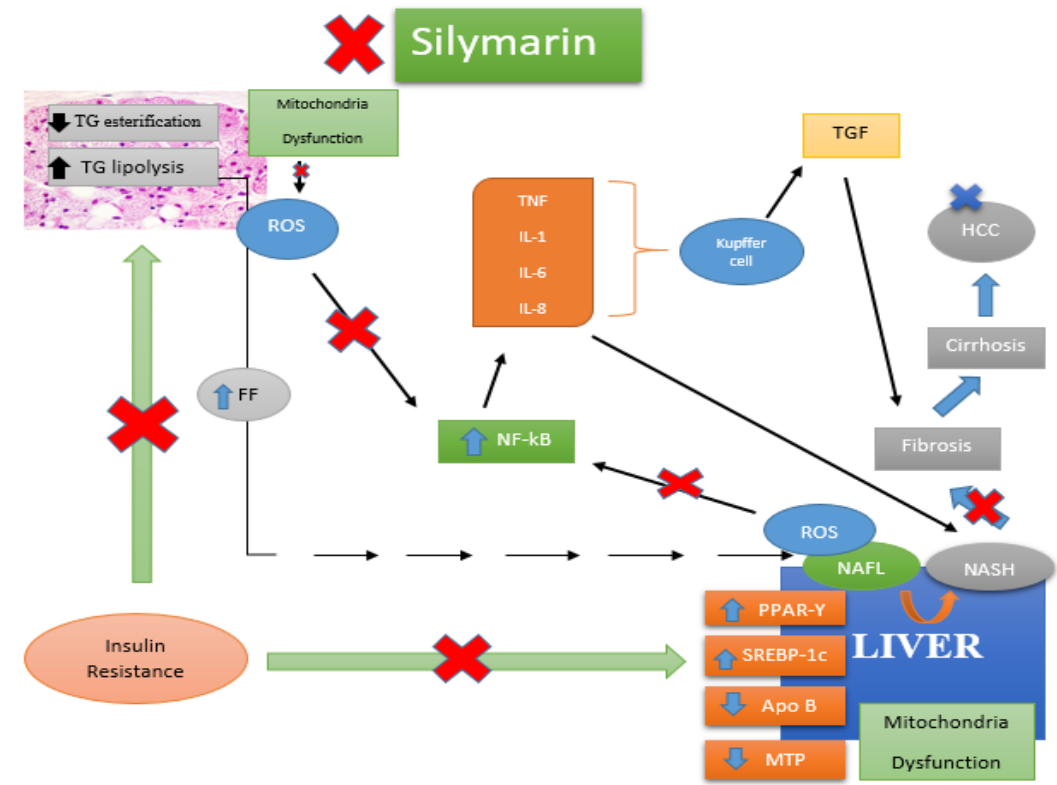

Fig. 9: Mechanism of Silymarin in Fatty liver disease

\section{Liver cirrhosis}

Cirrhosis is cause by long term damage of liver by hepatitis, alcoholic fatty liver disease and non-alcoholic fatty liver disease in which permanent scars are formed due to repeated damage of liver. Globally, $30 \%$ cases of cirrhosis are caused by hepatitis B and $27 \%$ cases caused by hepatitis C while $20 \%$ cases caused by alcoholic fatty liver disease. People with cirrhosis are at greater risk of developing the primary liver cancer (hepatocellular carcinoma), if persons are diagnosed with liver cirrhosis they immediately screened for HCC (Pearson \& Thomson, 2018).

\section{Herbal treatment of liver cirrhosis by Circumin}

Curcumin is one of the effective herbal drug use to treat liver cirrhosis. As liver cirrhosis is the damage of liver in result of any injury so it can be overcome by using the curcumin that neutralize the effects of different diseases on liver by some general mechanisms (Fig. 10). These mechanisms includes: 1) Decrease the activity of BAX and caspase III. These are the proteins that initiate the process of apoptosis. When these proteins are blocked, liver apoptosis will stop that leads to the liver cirrhosis. 2) Inflammatory pathway, circumin decrease the nicrosis factor as the result of which inflammatory pathway will not work. 3) In liver function, curcumin decrease the activity of alanine aminotransferase (ALT) and aspartate aminotransferase (AST) and protect the liver from any injury caused by these two enzymes. 4) Curcumin decreases the level of reactive oxygen species (ROS) and increase the level of glutathione that is an antioxidant and save liver from long term damage by any injury (Farzaei et al. 2018). 


\section{Curcumin}

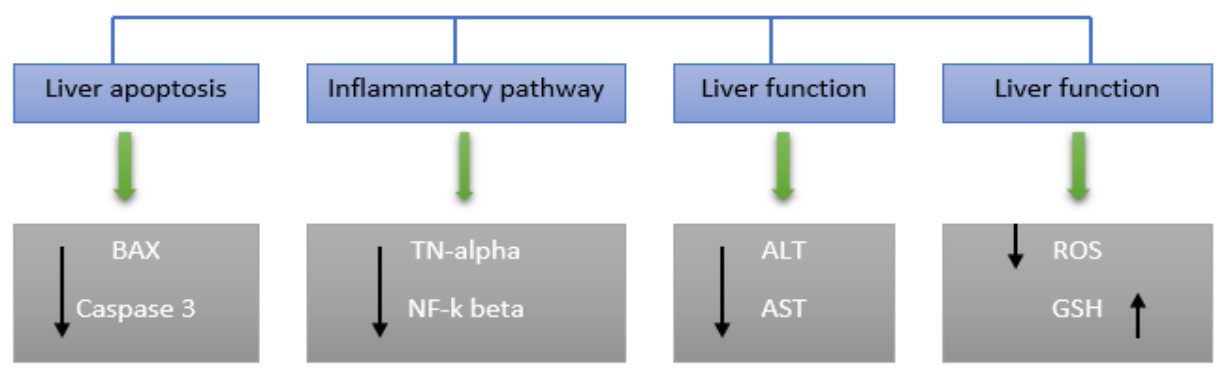

Fig. 10: Circumin mechanisms to treat liver cirrhosis

\section{Hepatocellular Carcinoma}

The $5^{\text {th }}$ most common type of liver cancer is hepatocellular carcinoma responsible for deaths of cancer patients worldwide. It is also called primary liver cancer and occurs in almost all populations but with higher rate of liver cancer in those males who consume alcohol, infected with HBV or HCV or increased iron stores (Fig. 11). The major risk factor for HCC is chronic hepatitis B in Asia while contamination of food and water is second major risk factor for HCC in Asian countries (El-Serag \& Rudolph, 2007).

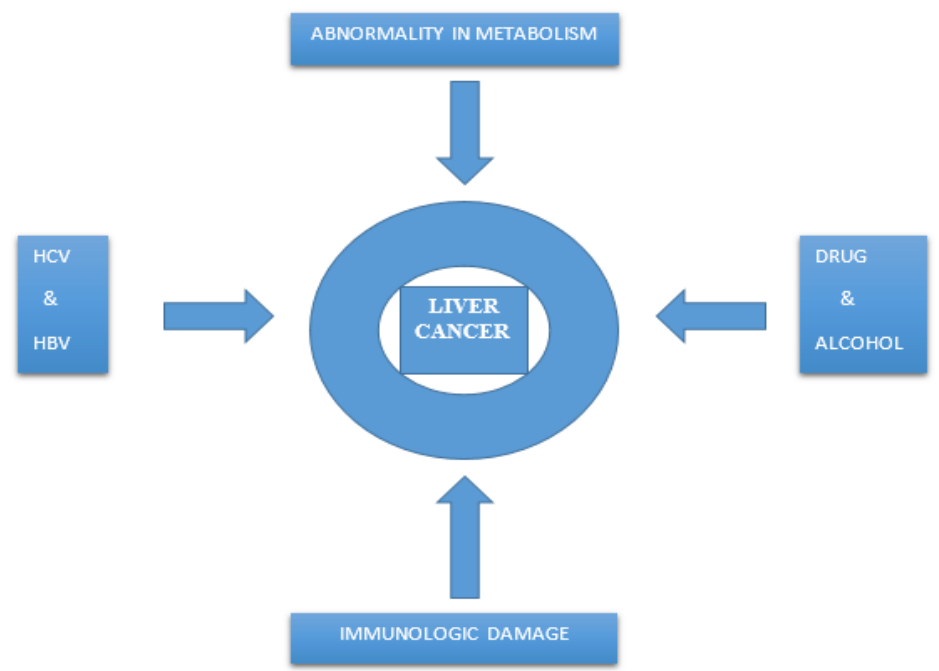

Fig. 11: Causes of liver cancer (HCC)

\section{Treatment of HCC by Circumin}

Cell cycle has 4 phases including G1 phase, S phase, G2 phase, mitotic phase. The cell cycle is regulated by cyclin proteins such as cyclin A, cyclin B, cyclin D1 and cyclin E that are responsible for the progression of cells from one phase of cell cycle to another phase. To inhibit the tumor cells growth curcumin is used as herbal medicine that have ability to interact with all these cyclin proteins and stop the division of cancerous cells at any stage of their life such as transformation, proliferation and invasion that leads to the formation 
and spread of tumor (Fig.12). This property of curcumin make it effective and very safest drug in the treatment of hepatocellular carcinoma by preventing the growth and further division of cancerous cells (Sa \& Das, 2018).

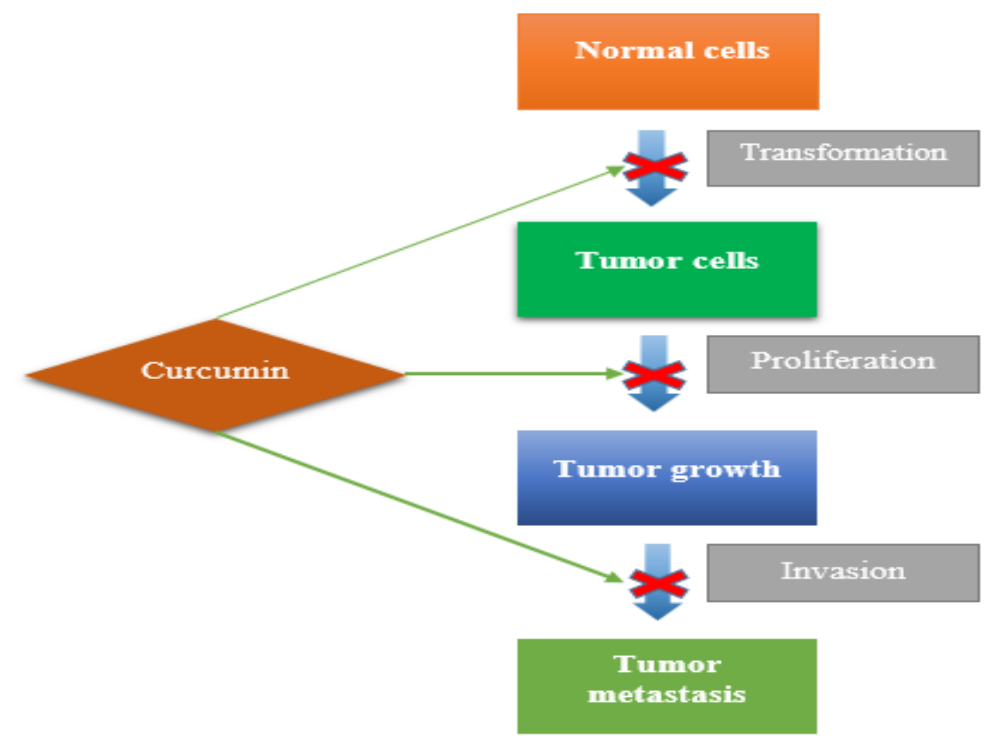

Fig. 12: Circumin mechanism to treat $\mathrm{HCC}$

\section{Carcinogenic effects of traditional herbal medicines}

A number of herbal medicines have not undergone testing for carcinogenicity (Table 7). However, the evidence of carcinogenicity is obtained from epidemiological studies that are observational in nature. The plant species that have adverse carcinogenic effects are given in table. These studies shows that the herbal medicines used for treatment of diseases may induce cancer and are not safe at all (Moreira et al., 2014).

Table 7: Carcinogenic effects of plant species

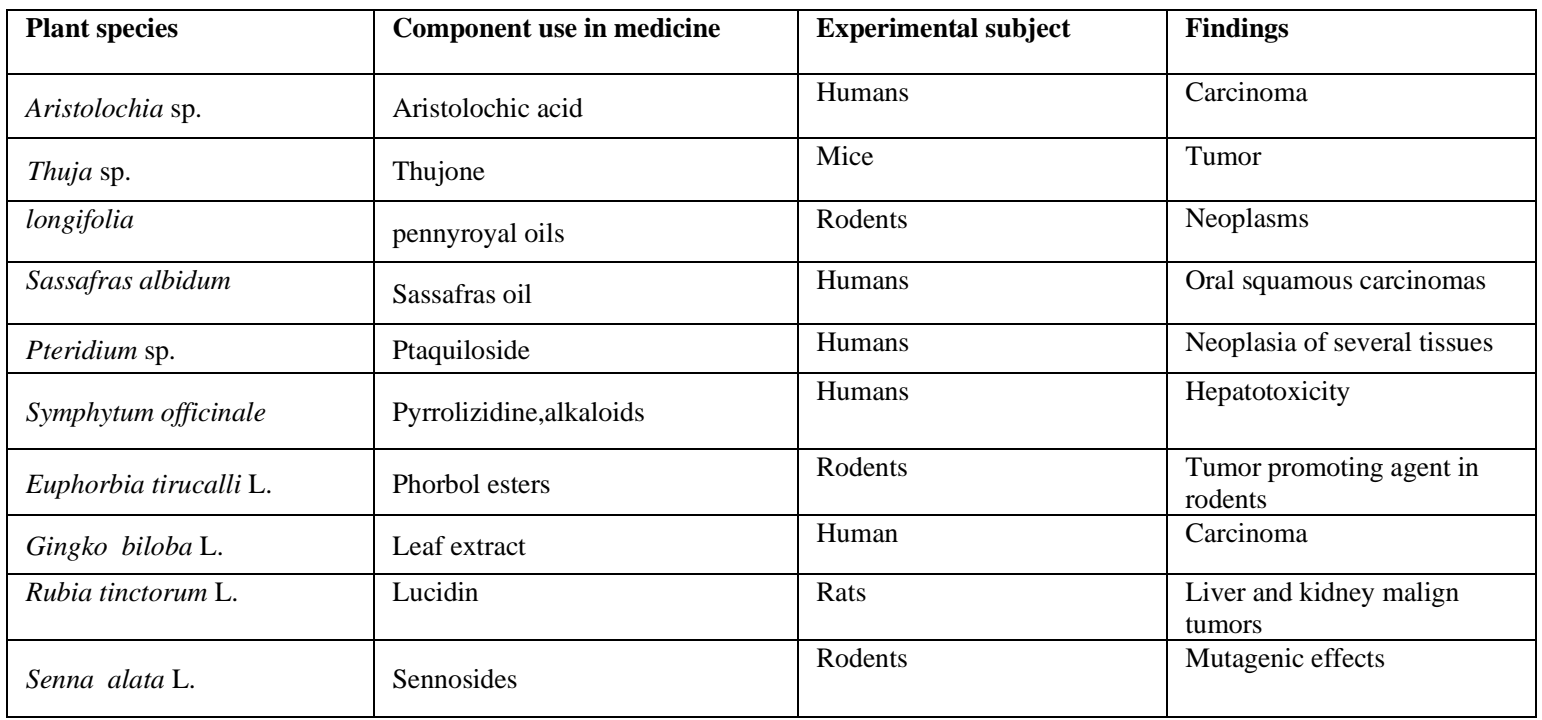




\section{Herbal medicines associated with liver injury}

Some herbal medicines induce liver toxicity that ranges from high level of liver enzyme such as alanine aminotransferase to jaundice that leads to liver failure or even death. The herbal medicines that are associated with liver injury are listed in table. These herbal constituents that have been used to treat the diseases from many years do not ensure the safety of drugs synthesized by the combination of herb and a synthetic drug (Shaw et al. 2012).

Table 8: plant species associated with liver damage

\begin{tabular}{|l|l|l|}
\hline Plant specie & Components & Experimental observations \\
\hline Larrea tridentata & Nordihydro guiarectic acid & $\begin{array}{l}\text { Hepatocellular injury } \\
\text { cholestatic, hepatitis }\end{array}$ \\
\hline Teucrium chamaedrys & Furanoditerpenoids & Hyperbilirubinemia, anorexia, nausea \\
\hline Piper methysticum G. & Piper- methysticin & Cholestasis pattern \\
\hline Symphytum officinale & Pyrrolizidine alkaloids & Budd-Chiari Syndrome \\
\hline Atractylis gummifera & Gummiferin & $\begin{array}{l}\text { Nephrotoxicity, } \\
\text { hepatorenal failure }\end{array}$ \\
\hline Callilepsis laureola & & Diarrhea, vomiting \\
\hline Chelidonium majus L. & Atractylosides & acute liver injury \\
\hline
\end{tabular}

\section{Future recommendations}

Herbal medicines are used from ancient time to treat diseases such as liver diseases, snakebite, skin infections, cancer, swelling and gastric ulcer. Unfortunately, there is no record found because only tribal/local people know that how to prepare and use herbs in the treatment of different diseases. The information of these medicinal plants is passed from generation to generation without maintaining any written record. World Health Organization have done many efforts for documenting all the information about medicinal plants from different parts of world. When all the herbal preparations used in different countries and different parts of world will be evaluated properly and scientifically in future, the people will get better treatment options for many diseases that cannot be treated because of lack of knowledge about specific disease and its corresponding medicinal plant. These herbs can be used in combinations with many pharmaceutical/synthetic drugs that are used in the treatment of diseases but have adverse side effects on human health which will make their performance far better from today. The WHO is looking at the countries like India and Japan that have most distinct and diverse species of medicinal plants because they are the top suppliers of herbal plants as raw material. As herbal medicines are safe and cheaper from other therapeutic drugs, so the research on medicinal plants will continue in future.

\section{Summary}

Herbal treatment is one of the most commonly used alternative and complementary therapy for treatment of liver diseases. These medicines such as silymarin, curcumin, glycyrrhizic acid and camellia are used to treat common liver diseases such as hepatitis, liver cirrhosis, hepatocellular carcinoma and fatty liver disease that 
decrease the prevalence of liver diseases in different regions of world where these diseases were most common. According to the World Health Organization estimates in last 5 years, the prevalence of liver diseases has been decreased to such extent that it can be controllable now, herbal treatments play an important role in prevention of these diseases by controlling the virus that cause hepatitis.

Now a days $18 \%$ liver diseases are cured by phytochemicals or plant extracts that are obtained from different botanical plants. Beside all these herbal plants, there are some natural plants that are now being researched by scientists to treat liver injuries, such plants include coffee that work to treat liver cirrhosis and liver cancer, apple that work as an oxidant and decrease the incidence of reactive oxygen species, resveratrol is used to treat non-alcoholic fatty liver disease. However, there are some herbal related injuries of liver that are caused by several herbal plants that produce carcinogenic effects on liver. But still herbal medicines are the products that produce very less toxic effects on liver as compared to the pharmaceutical drugs that are also been used for prevention and treatment of common liver diseases.

\section{Conclusion}

This article describes the impact of medicinal plants and their mechanism of action in the treatment of common liver diseases including liver cancer, cirrhosis, fatty liver disease and hepatitis. The recent studies on herbal medicine shows that it is one of the best effective method to treat the common liver diseases. The herbal plants have antioxidant, anti-inflammatory effects that can be used in liver ailments because they can protect the liver from injuries, as well as some herbs are discovered that have hepatoprotective effects and antiviral activity that can stop the development and growth of cancerous cells. By use of such herbs, the prevalence of hepatocellular carcinoma has been decreased to a surprising extent. Now a days $18 \%$ liver diseases are cured by phytochemicals or plant extracts that are obtained from different botanical plants. The further studies elaborated the efficacy of these phytochemicals that are now been used most commonly as compared to pharmaceuticals drugs. The reports of World Health Organization (WHO) showed that the incidence of liver diseases is much lesser than the estimated incidence of about 5 years from 2012 to 2015. Some herbs have hepatoprotective effects but induce the liver damage as well as carcinogenic effects, the further research on these herbal medicines to use them in combinations with pharmaceutical drugs to make their effect better is continued.

\section{References}

Akbar, M. U., Rehman, K., Zia, K. M., Qadir, M. I., Akash, M. S. H., \& Ibrahim, M. (2018). Critical Review on Curcumin as a Therapeutic Agent: From Traditional Herbal Medicine to an Ideal Therapeutic Agent. Critical Reviews in Eukaryotic Gene Expression, 28(1), 17-24.

Asrani, S. K., Larson, J. J., Yawn, B., Therneau, T. M., \& Kim, W. R. (2013). Underestimation of liverrelated mortality in the United States. Gastroenterology, 145(2), 375-382.

Bahmani, M., Shirzad, H., Rafieian, S., \& Rafieian-Kopaei, M. (2015). Silybum marianum: beyond hepatoprotection. Journal of Evidence-Based Complementary \& Alternative Medicine, 20(4), 292301.

Balaban, Y. H., Aka, C., \& Koca-Caliskan, U. (2017). Liver immunology and herbal treatment. World journal of hepatology, 9(17), 757-770.

Baliga, M. S., Jimmy, R., Thilakchand, K. R., Sunitha, V., Bhat, N. R., Saldanha, E., \& Palatty, P. L. (2013). Ocimum sanctum L (Holy Basil or Tulsi) and its phytochemicals in the prevention and treatment of cancer. Nutrition and Cancer, 65(1), 26-35.

Blach, S., Zeuzem, S., Manns, M., Altraif, I., Duberg, A. S., Muljono, D. H., \& Abaalkhail, F. (2017). Global prevalence and genotype distribution of hepatitis $\mathrm{C}$ virus infection in 2015: a modelling study. The Lancet Gastroenterology \& Hepatology, 2(3), 161-176.

Chen, X., Oidovsambuu, O., Liu, P., Grosely, R., Elazar, M., Winn, V. D., \& Yagaanbuyant, D. (2017). A novel quantitative microarray antibody capture assay identifies an extremely high hepatitis delta virus prevalence among hepatitis B virus-infected mongolians. Hepatology, 66(6), 1739-1749.

Debing, Y., Moradpour, D., Neyts, J., \& Gouttenoire, J. (2016). Update on hepatitis E virology: Implications for clinical practice. Journal of Hepatology, 65(1), 200-212. 
El-Serag, H. B., \& Rudolph, K. L. (2007). Hepatocellular carcinoma: epidemiology and molecular carcinogenesis. Gastroenterology, 132(7), 2557-2576.

Farzaei, M., Zobeiri, M., Parvizi, F., El-Senduny, F., Marmouzi, I., Coy-Barrera, E., \& Abdollahi, M. (2018). Curcumin in liver diseases: A systematic review of the cellular mechanisms of oxidative stress and clinical perspective. Nutrients, 10(7), 855-857.

Federico, A., Dallio, M., \& Loguercio, C. (2017). Silymarin/silybin and chronic liver disease: a marriage of many years. Molecules, 22(2), 191-206.

Franco, E., Meleleo, C., Serino, L., Sorbara, D., \& Zaratti, L. (2012). Hepatitis A: epidemiology and prevention in developing countries. World Journal of Hepatology, 4(3), 68-73.

Hidaka, I., Hino, K., Korenaga, M., Gondo, T., Nishina, S., Ando, M., \& Sakaida, I. (2007). Stronger NeoMinophagen $\mathrm{C}^{\mathrm{TM}}$, a glycyrrhizin-containing preparation, protects liver against carbon tetrachlorideinduced oxidative stress in transgenic mice expressing the hepatitis $\mathrm{C}$ virus polyprotein. Liver International, 27(6), 845-853.

Kshirsagar, A., Vetal, Y., Ashok, P., Bhosle, P., \& Ingawale, D. (2008). Drug induced hepatotoxicity: a comprehensive review. Internet $J$ Pharmacol, 7, 1-13.

Li, J. Y., Cao, H. Y., Liu, P., Cheng, G. H., \& Sun, M. Y. (2014). Glycyrrhizic acid in the treatment of liver diseases: literature review. BioMed Research International, 2014(1), 847-862.

Lin, C. L., \& Kao, J. H. (2017). Natural history of acute and chronic hepatitis B: the role of HBV genotypes and mutants. Best Practice \& Research Clinical Gastroenterology, 31(3), 249-255.

Mokdad, A. A., Lopez, A. D., Shahraz, S., Lozano, R., Mokdad, A. H., Stanaway, J., \& Naghavi, M. (2014). Liver cirrhosis mortality in 187 countries between 1980 and 2010: a systematic analysis. BMC Medicine, 12(1), 145-158.

Moreira, D. D. L., Teixeira, S. S., Monteiro, M. H. D., De-Oliveira, A. C. A., \& Paumgartten, F. J. (2014). Traditional use and safety of herbal medicines. Revista Brasileira de Farmacognosia, 24(2), 248257.

Mysore, K. R., \& Leung, D. H. (2018). Hepatitis B and C. Clinics in Liver Disease, 22(4), 703-722.

Park, H. J., DiNatale, D. A., Chung, M. Y., Park, Y. K., Lee, J. Y., Koo, S. I., ... \& Bruno, R. S. (2011). Green tea extract attenuates hepatic steatosis by decreasing adipose lipogenesis and enhancing hepatic antioxidant defenses in ob/ob mice. The Journal of Nutritional Biochemistry, 22(4), 393-400.

Pearson, J., \& Thomson, E. (2018). Decompensated liver cirrhosis. Anaesthesia \& Intensive Care Medicine, 19(3), 101-106.

Prasad, S., Gupta, S. C., \& Tyagi, A. K. (2017). Reactive oxygen species (ROS) and cancer: role of antioxidative nutraceuticals. Cancer Letters, 387, 95-105.

Rajaratnam, M., Prystupa, A., Lachowska-Kotowska, P., Zaluska, W., \& Filip, R. (2014). Herbal medicine for treatment and prevention of liver diseases. Journal of Pre-Clinical and Clinical Research, 8(2), $55-60$.

Rehm, J., Samokhvalov, A. V., \& Shield, K. D. (2013). Global burden of alcoholic liver diseases. Journal of hepatology, 59(1), 160-168.

Rinella, M., \& Charlton, M. (2016). The globalization of nonalcoholic fatty liver disease: prevalence and impact on world health. Hepatology, 64(1), 19-22.

Rodriguez-Casado, A. (2016). The health potential of fruits and vegetables phytochemicals: notable examples. Critical reviews in Food Science and Nutrition, 56(7), 1097-1107.

Sa, G., \& Das, T. (2008). Anticancer effects of curcumin: cycle of life and death. Cell Division, 3(1), 1-14.

Seeff, L. B., Bonkovsky, H. L., Navarro, V. J., \& Wang, G. (2015). Herbal products and the liver: a review of adverse effects and mechanisms. Gastroenterology, 148(3), 517-532.

Shankar, H., Blanas, D., Bichoupan, K., Ndiaye, D., Carmody, E., Martel-Laferriere, V., \& Nichols, K. (2016). A novel collaborative community-based hepatitis B screening and linkage to care program for African immigrants. Clinical Infectious Diseases, 62(4), 289-297.

Sharma, S., Rana, S., Patial, V., Gupta, M., Bhushan, S., \& Padwad, Y. S. (2016). Antioxidant and hepatoprotective effect of polyphenols from apple pomace extract via apoptosis inhibition and Nrf2 activation in mice. Human \& Experimental Toxicology, 35(12), 1264-1275. 
Shaw, D., Graeme, L., Pierre, D., Elizabeth, W., \& Kelvin, C. (2012). Pharmacovigilance of herbal medicine. Journal of Ethnopharmacology, 140(3), 513-518.

Stanaway, J. D., Flaxman, A. D., Naghavi, M., Fitzmaurice, C., Vos, T., Abubakar, I., Forouzanfour, M. H. (2016). The global burden of viral hepatitis from 1990 to 2013: findings from the Global Burden of Disease Study 2013. The Lancet, 388(10049), 1081-1088.

Stickel, F., \& Schuppan, D. (2007). Herbal medicine in the treatment of liver diseases. Digestive and Liver Disease, 39(4), 293-304.

Tong, S., \& Revill, P. (2016). Overview of hepatitis B viral replication and genetic variability. Journal of Hepatology, 64(1), 4-16.

Vargas-Mendoza, N., Madrigal-Santillán, E., Morales-González, A., Esquivel-Soto, J., Esquivel-Chirino, C., y González-Rubio, M. G. L., \& Morales-González, J. A. (2014). Hepatoprotective effect of silymarin. World journal of Hepatology, 6(3), 144-149.

Wadhawan, M., \& Anand, A. C. (2016). Coffee and liver disease. Journal of Clinical and Experimental Hepatology, 6(1), 40-46.

Wu, Y. H. (2016). Naturally derived anti-hepatitis B virus agents and their mechanism of action. World Journal of Gastroenterology, 22(1), 188-204.

Xiong, F., \& Guan, Y. S. (2017). Cautiously using natural medicine to treat liver problems. World Journal of Gastroenterology, 23(19), 3388-3395.

Zhang, A., Sun, H., \& Wang, X. (2013). Recent advances in natural products from plants for treatment of liver diseases. European Journal of Medicinal Chemistry, 63, 570-577.

Zhao, G., Han, X., Zheng, S., Li, Z., Sha, Y., Ni, J., \& Song, Z. (2016). Curcumin induces autophagy, inhibits proliferation and invasion by downregulating AKT/mTOR signaling pathway in human melanoma cells. Oncology Reports, 35(2), 1065-1074. 